\title{
COLUMN
}

\section{Recognition and appreciation}

These days, I know a lot of scientists, mainly young ones, who don't feel like climbing further up the career ladder in the present system. A major consideration is the workload and the pressure to publish, combined with the growing challenge of finding funding, especially in this Covid

crisis. I'm

'If it's so difficult

to think of ways

to recognize and

appreciate your

employees, that

says something

too"

hearing more and more people saying they just want to leave. The only lifebelt these drowning academics

get thrown if they grumble about this is the dossier called Recognition and Appreciation, which WUR has been working on for some time. In November 2019, research organizations VSNU, NFU, KNAW, NWO and ZonMw published a position paper called Space for everyone's talent: towards a new balance in the recognition and appreciation of scientists. The idea is that there should be a wider appreciation of the work of scientists, with 'less emphasis on the number of publications, and more emphasis on the other aspects of a scientist's work, such as

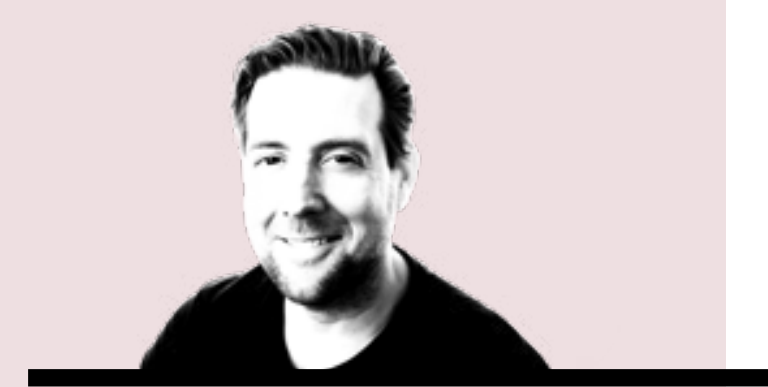

\section{Guido Camps}

education and impact. This broader form of recognition and appreciation is a better match with the current core business of scientific and educational institutions, and with what society asks of them.'

This report from 2019 (!) led in

Wageningen to a committee being formed, which will give a presentation in December 2021, based on a survey done in April 2021. The invitation says that, besides the results of the survey, the presentation will include a proposal on 'how to proceed on the basis of propositions. We are looking forward to discussing the results and the next steps with you, in order to arrive at an improved approach to recognition and appreciation within WU'. The question is: how quickly can this result in real change? This slow pace of action is a dangerous gamble by the university at a time when other universities have already taken steps, the labour market is historically tight, and the workload is only increasing. If you find it so difficult to think of ways to recognize and appreciate your employees, that says something too. Come on WUR, make your reputation as the best university true for your staff as well as your students. 